\title{
Predicting real-time coagulant dosage in water treatment by artificial neural networks and adaptive network-based fuzzy inference system
}

\author{
Guan-De Wu, Shang-Lien Lo*

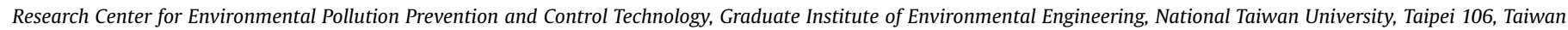

\section{A R T I C L E I N F O}

\section{Article history:}

Received 30 April 2007

Received in revised form

6 January 2008

Accepted 23 March 2008

Available online 3 June 2008

Keywords:

Coagulant dosage

Artificial neural networks

Adaptive network-based fuzzy inference

system

Water treatment

\begin{abstract}
A B S T R A C T
Coagulation is an important component of water treatment. Determining the optimal coagulant dosage is vital, as insufficient dosage will result in unqualified water quality. Traditionally, jar tests and operators' own experience are used to determine the optimum coagulant dosage. However, jar tests are time-consuming and less adaptive to changes in raw water quality in real time. When an unusual condition occurs, such as a heavy rain, the storm water brings high turbidity to water source, and the treated effluent quality may be inferior to drinking water quality standards, because the conventional operation method can be hardly in time to adjust to the proper dosage. An optimal modeling can be used to overcome these limitations. In this paper, artificial neural network (ANN) and adaptive networkbased fuzzy inference system (ANFIS) models were used to model poly aluminum chloride (PAC) dosing of northern Taiwan's surface water. Each of them was built based on 819 sets of process-controlled data. The performance of the models was found to be sufficient. Two simulation tools, ANN and ANFIS, were developed that enabled operators to obtain real-time PAC dosage more easily. The self-predicting model of ANFIS is better than ANN for PAC dosage predictions.
\end{abstract}

(c) 2008 Elsevier Ltd. All rights reserved.

\section{Introduction}

The treatment of drinking water provides multiple barriers to protect public health by removing microorganisms and chemicals that may cause illness to consumers. The removal of turbidity and color to produce water that is aesthetically acceptable to consumers is a very important component of water treatment. Water treatment consists of a sequence of complex physical and chemical processes; currently, in many water treatment plants (WTP), process control is generally accomplished through examining the quality of the product water and adjusting the processes through an operator's own experience and jar tests. This practice is inefficient and slow in controlling responses. With more stringent requirements being placed on water treatment performance, operators needed a reliable tool to optimize the process controlling in WTP. Much of the difficulty in modeling water treatment processes can be related to complex interactions among many influential water quality factors, and many chemical and physical reactions. In modeling water treatment processes, the major challenge is to establish the nonlinear relationships between the inputs and outputs of each process. In this paper, one such tool is presented, which is a process control system

\footnotetext{
* Corresponding author. Tel.: +8862 23625373; fax: +8862 23928821.

E-mail address: sllo@ntu.edu.tw (S.-L. Lo).
}

built with the artificial neural network (ANN) modeling or adaptive network-based fuzzy inference system (ANFIS) modeling approach.

The coagulation process is the most important in WTP. The coagulant of WTP in this study is poly aluminum chloride (PAC). Traditionally, optimum coagulant dosages are determined using jar tests. However, jar tests are relatively expensive and timeconsuming. Consequently, jar tests are generally only carried out periodically (Yu et al., 2000), which means that they are reactive, rather than proactive, as coagulant dosage is continuously changing when responding to the occurrence of water quality problems. In addition, as a result of the amount of time it takes to conduct jar tests, they cannot be used in responding to rapid changes in raw water quality (Joo et al., 2000), and thus are not suitable to real-time control (Yu et al., 2000).

In some previous studies, ANNs were used to develop process models for simulating the alum dosing process. For example, Zhang and Stanley (1999) and Baxter et al. (1999) developed ANN models for predicting treated water turbidity and color, respectively, at the Rossdale WTP in Edmonton, Alberta, Canada. Gagnon et al. (1997) developed an ANN model for predicting the optimal alum dosage for the Ste-Foy WTP in Quebec, Canada. Joo et al. (2000) developed a similar model for Chungju WTP in Korea, and van Leeuwen et al. (1999) developed an ANN model for the prediction of optimal alum dosage based on jar tests conducted on surface waters collected in southern Australia. Holger et al. (2004) 
used the same database as van Leeuwen et al. (1999) to predict optimal alum dosage and treated water quality parameters. Deveughele and Do-Quang (2004) developed SUEZ ENVIRONNEMENT, which was built by self-organizing features map and multilayer perceptron (MLP), to predict the optimal coagulant dosage in the WTP, which is located at Viry in the vicinity of Paris. Bae et al. (2006) developed the model in which the coagulant type was determined by decision tree rules and dosage was estimated by neural network models that perform mapping between the water quality (e.g. pH, turbidity, alkalinity, water temperature, etc.) and coagulants (e.g. PAC, PASS and PSO-M). Chen and Hou (2006) developed a practical feedforward control system with fuzzy feedback trim, which is presented for controlling the coagulant dosage strategy of the Changhsing Water Purification Plant of Taipei Water Department. Benardos and Vosniakos (2007) developed a methodology for determining the best architecture that is based on the use of a genetic algorithm (GA) and the development of novel criteria that quantify an ANN's performance (both training and generalization) as well as its complexity.

In all of the above studies, the model inputs consisted of raw water parameters, whereas the model output was the optimal alum dosage needed to achieve the desired treated water quality. Zhang and Stanley (1999) included the turbidity of the treated water as an input in addition to a number of raw water quality parameters in their ANN model for predicting the optimal alum dosage at the Rossdale WTP. Yu et al. (2000) did the same in their model for the prediction of optimal alum dosage at a WTP in Taipei City, Taiwan. Chun et al. (1999) used the ANFIS for coagulant dosing process in a water purification plant.

In all of the above studies, the raw water quality was more stable, not changing, e.g. when an unusual condition occurs, such as a heavy rain, the storm water brings high turbidity to water source. Otherwise, when influent water does not provide information on water quality, the predicting model cannot be used. Based on these concepts, a project was initiated to study the potential capacity of ANN and ANFIS process control in WTP. This study was conducted at the WTP in Taipei County, Taiwan, having a water purification capacity of 1,200,000 CMD. The objective of this study was to select a section of the water treatment processes, collect real operational data, build, and test the ANN and ANFIS predicting model. The treatment processes include the coagulation, flocculation, sedimentation, filtration, and disinfection process (Fig. 1).

In this paper, the principal concepts of using the ANN and ANFIS in the water treatment modeling and process control are introduced. The ANN and ANFIS focus on finding a repeated, recognizable, and predictable pattern(s) between the causes and the

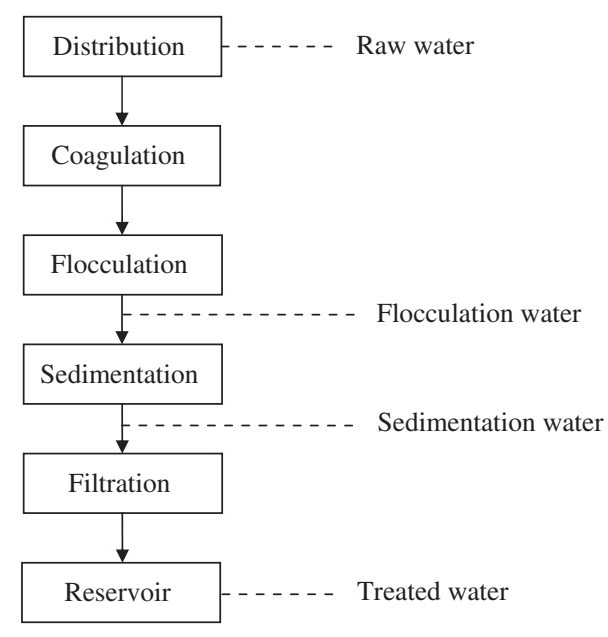

Fig. 1. The WTP in Taipei Country, Taiwan Layout. effects from the past operation data records. The ANN and ANFIS modeling approach does not require a description of how the processes occur in either the micro- or macro-environments, but only the knowledge of important factors that governed the process. This situation makes the ANN and ANFIS modeling approach a rational choice for process modeling and controlling in water treatment. Once reliable ANN and ANFIS process models are developed, it can be integrated into a process-controlled architecture.

\section{Methodology}

\subsection{Data collection}

In this research, both ANN and ANFIS models that were developed are capable of assisting treatment plant operators with determining real-time PAC dosage for WTP in Taipei County, Taiwan. The WTP in this study is a conventional treatment facility consisting of coagulation, flocculation, sedimentation, and filtration.

In order to obtain the input/output data required to develop and validate ANN and ANFIS models, water samples were collected from WTP in Taipei County, Taiwan. The desired water quality parameters were measured, including the turbidity, $\mathrm{pH}$, color, and temperature of each raw, flocculation, sedimentation, and treated water (Table 1 ).

\subsection{The index}

Inputs to the model predicting PAC dosage parameters were the water quality parameters of each process in a WTP and prior PAC dosage. The model output was the PAC dosage. The input parameters include the PAC dosage of yesterday, PAC dosage before yesterday, and the temperature, turbidity, color, $\mathrm{pH}$ in each of the raw, flocculation, sedimentation, and treated water. The input parameters were decided on the Pearson factor $(r)$ with the real-time PAC dosage:

$$
r=\frac{n\left(\sum x y\right)-\left(\sum x\right)\left(\sum y\right)}{\sqrt{\left[n \sum x^{2}-\left(\sum x\right)^{2}\right]\left[n \sum y^{2}-\left(\sum y\right)^{2}\right]}}
$$

where $n$ is the number of data, $x, y$ are the values of parameters. In this study, $x$ was the input parameter and $y$ was the output parameter. The Pearson factor of each input and output was calculated as shown in Table 2 .

A root-mean-square normalized error (RMSE) is used as a performance index to compare the prediction capability of ANN trained by each data set. The RMSE is known to be descriptive when the prediction capability among predictors is compared (Zurada, 1992):

RMSE $=\frac{1}{n} \sqrt{\sum_{i=1}^{n}\left(o_{\mathrm{p}}-o_{\mathrm{d}}\right)^{2}}$

where $n$ is the number of data, $o_{\mathrm{p}}$ is the predicted value and $o_{\mathrm{d}}$ is the real operating value.

The correlation coefficient $\left(R^{2}\right)$ indicator compares the performance of the model with that of a naive benchmark model, the output of which is the mean of all samples (Baxter et al., 1999). It can therefore be used to compare the relative performance of the models for different model outputs.

\subsection{ANN model}

The 819 data points were divided into two subsets using the method proposed. These subsets are: (i) a training set for 
Table 1

The water quality of each process of the WTP in Taipei County, Taiwan

\begin{tabular}{|c|c|c|c|c|}
\hline $\begin{array}{l}\text { Water sample } \\
\text { Sampling point }\end{array}$ & $\begin{array}{l}\text { Raw water } \\
\text { Distribution }\end{array}$ & $\begin{array}{l}\text { Flocculation water } \\
\text { Flocculation }\end{array}$ & $\begin{array}{l}\text { Sedimentation water } \\
\text { Sedimentation }\end{array}$ & $\begin{array}{l}\text { Treated water } \\
\text { Reservoir }\end{array}$ \\
\hline Temperature $\left({ }^{\circ} \mathrm{C}\right)$ & $\begin{array}{l}22.1^{\mathrm{a}} \\
(12-31)^{\mathrm{b}}\end{array}$ & $\begin{array}{l}22.1 \\
(12-31)\end{array}$ & $\begin{array}{l}22.1 \\
(12-31)\end{array}$ & $\begin{array}{l}22.1 \\
(12-31)\end{array}$ \\
\hline Turbidity (NTU) & $\begin{array}{l}60.4 \\
(3.4-1950)\end{array}$ & $\begin{array}{l}60.5 \\
(1.8-2100)\end{array}$ & $\begin{array}{l}4.2 \\
(0.6-25)\end{array}$ & $\begin{array}{l}1.6 \\
(0.3-16)\end{array}$ \\
\hline Color (HU) & $\begin{array}{l}17.9 \\
(5-375)\end{array}$ & $\begin{array}{l}16.0 \\
(1-350)\end{array}$ & $\begin{array}{l}5 \\
(1-8)\end{array}$ & $\begin{array}{l}5 \\
(1-5)\end{array}$ \\
\hline $\mathrm{pH}$ & $\begin{array}{l}7.8 \\
(7-8.9)\end{array}$ & $\begin{array}{l}7.3 \\
(6.3-7.9)\end{array}$ & $\begin{array}{l}7.2 \\
(6.4-7.9)\end{array}$ & $\begin{array}{l}7.2 \\
(6.3-7.9)\end{array}$ \\
\hline
\end{tabular}

average of data.

${ }^{b}$ Ranges of data.

Table 2

The Pearson factor of each input and output

\begin{tabular}{|c|c|c|c|c|c|c|c|c|c|c|c|c|c|c|c|}
\hline & & \multirow[b]{2}{*}{ PAC } & \multirow[t]{2}{*}{ Tem. } & \multicolumn{4}{|c|}{ Turbidity } & \multicolumn{4}{|l|}{ Color } & \multicolumn{3}{|l|}{$\mathrm{pH}$} & \multirow[b]{2}{*}{ TW } \\
\hline & & & & RW & FW & SW & TW & RW & FW & SW & TW & RW & FW & SW & \\
\hline & PAC & 1.000 & 0.133 & 0.608 & 0.596 & 0.302 & 0.410 & 0.496 & 0.500 & 0.002 & 0.026 & -0.109 & -0.424 & -0.469 & -0.489 \\
\hline Tem. & & & 1.000 & 0.086 & 0.080 & -0.152 & -0.158 & 0.162 & 0.163 & -0.010 & 0.015 & 0.251 & -0.310 & -0.296 & -0.221 \\
\hline \multirow[t]{4}{*}{ Turbidity } & RW & & & 1.000 & 0.964 & 0.483 & 0.435 & 0.628 & 0.628 & 0.006 & 0.014 & 0.018 & -0.368 & -0.379 & -0.414 \\
\hline & FW & & & & 1.000 & 0.513 & 0.415 & 0.611 & 0.614 & 0.005 & 0.013 & 0.008 & -0.379 & -0.390 & -0.430 \\
\hline & SW & & & & & 1.000 & 0.344 & 0.289 & 0.282 & -0.037 & -0.032 & -0.018 & -0.177 & -0.187 & -0.253 \\
\hline & TW & & & & & & 1.000 & 0.161 & 0.153 & -0.001 & 0.032 & -0.116 & -0.291 & -0.319 & -0.328 \\
\hline \multirow[t]{4}{*}{ Color } & RW & & & & & & & 1.000 & 0.991 & 0.010 & 0.023 & 0.045 & -0.283 & -0.338 & -0.392 \\
\hline & FW & & & & & & & & 1.000 & 0.008 & 0.021 & 0.062 & -0.263 & -0.317 & -0.366 \\
\hline & SW & & & & & & & & & 1.000 & 0.800 & -0.069 & 0.026 & 0.016 & 0.012 \\
\hline & TW & & & & & & & & & & 1.000 & -0.099 & -0.029 & -0.031 & -0.047 \\
\hline \multirow[t]{4}{*}{$\mathrm{pH}$} & RW & & & & & & & & & & & 1.000 & 0.385 & 0.368 & 0.417 \\
\hline & FW & & & & & & & & & & & & 1.000 & 0.953 & 0.904 \\
\hline & SW & & & & & & & & & & & & & 1.000 & 0.939 \\
\hline & TW & & & & & & & & & & & & & & 1.000 \\
\hline
\end{tabular}

PAC: the PAC dosage, Tem. : temperature, RW: raw water, FW: flocculation water, SW: sedimentation water, TW: treated water.

adjusting the connection weights, and (ii) a testing set for checking the model ability. The databases were divided into 699 and 120 data points in the training and testing sets, respectively. The input data were scaled linearly between 0.0 and 1.0 to be commensurate with the limits of the transfer function in the ANN output layer (sigmoidal). The training epochs were 1000 times. According to Pearson factor, the number of model inputs used in this study ranged from 1 to 6 . There were 17 models in this study (Table 3).

The ANN architecture consisted of a MLP. MLPs have already been used successfully for the prediction of coagulant dosage (Baxter et al., 1999). The optimum number of hidden layers and the optimum number of nodes in each of these was found by trial and error. Although it has been proven that a network with one hidden layer can approximate any continuous function, given sufficient degrees of freedom (Hornik et al., 1989), other studies have also suggested similar ideologies. Therefore, the use of one hidden layer was considered.

The optimum number of hidden layer nodes was also found by trial and error. The maximum number of nodes considered in each hidden layer was $2 I+1$, where $I$ is the number of model inputs, as this has been shown to be the upper limit required to model any continuous function for networks with one hidden layer (HechtNielsen, 1987). This was considered reasonable, as similar relationships are not available for networks with more than one hidden layer.

The models were calibrated using the back-propagation (BPN) algorithm, as it has already been used successfully for the prediction of coagulant dosage (van Leeuwen et al., 1999) and
Table 3

The input of each ANN model

\begin{tabular}{llllllll} 
Group & Parameter & PAC $(t-2)$ & PAC $(t-1)$ & RWT $(t)$ & FWT $(t)$ & RWC $(t)$ & FWC $(t)$ \\
& $r$ & 0.749 & 0.822 & 0.608 & 0.596 & 0.496 & 0.500 \\
& Code & & & & & & \\
\hline ANN1 & AN001 & & & I & I & I & I \\
& AN002 & & I & I & & I \\
& AN003 & & I & I & & \\
& AN004 & & & I & & \\
ANN2 & AN005 & & & I & & & I \\
& AN002n & & I & I & I & I & I \\
& AN003n & I & I & I & & \\
& AN004n & I & I & I & & \\
& AN005n & I & & I & & I \\
ANN33 & AN001nn & I & I & I & & & \\
& AN002nn & I & I & I & I & I & \\
& AN003nn & I & I & I & I & & \\
& AN004nn & I & I & & I & & \\
AN005nn & I & I & I & & & \\
ANN4 & AN006n & & I & & & & \\
AN006nn & I & I & & & &
\end{tabular}

PAC $(t-1)$ : the PAC dosage yesterday, PAC $(t-2)$ : the PAC dosage before yesterday, RWT $(t)$ : the turbidity of raw water today, FWT $(t)$ : the turbidity of flocculation water today, RWC $(t)$ : the color of raw water today, FWC $(t)$ : the color of flocculation water today; $r$ : the Pearson factor between PAC $(t)$ and each parameter.

has the ability to escape local minima in the error surface (White, 1989). Optimal values on the parameters of controlling the size of the steps taken in weight space as part of the BPN algorithm 
(i.e. learning rate and momentum values) were found by trial and error. Cross-validation was used as the stopping criterion to avoid overfitting of the training data.

The models were validated using the 120 validation samples in order to test the generalization ability of the models over the range of the data used for training. It should be noted that the validation data were not used in the model development process in any capacity. As the test set was used to determine the optimal network geometry, parameters of controlling the BPN algorithm and to decide when to stop training.

\subsection{ANFIS model}

The adaptive ANFIS was developed by Jang (1993). The architecture of the ANFIS is shown in Fig. 2. Generally, the premise parameters are tuned by BPN at the backward pass in the ANFIS model. By using this BPN learning procedure, we can minimize the error between the desired output and the fuzzy model output. In another application study, Inan and Elif Derya (2005) used an adaptive neuro-fuzzy inference system for detection of ophthalmic arterystenosis, and the results confirmed

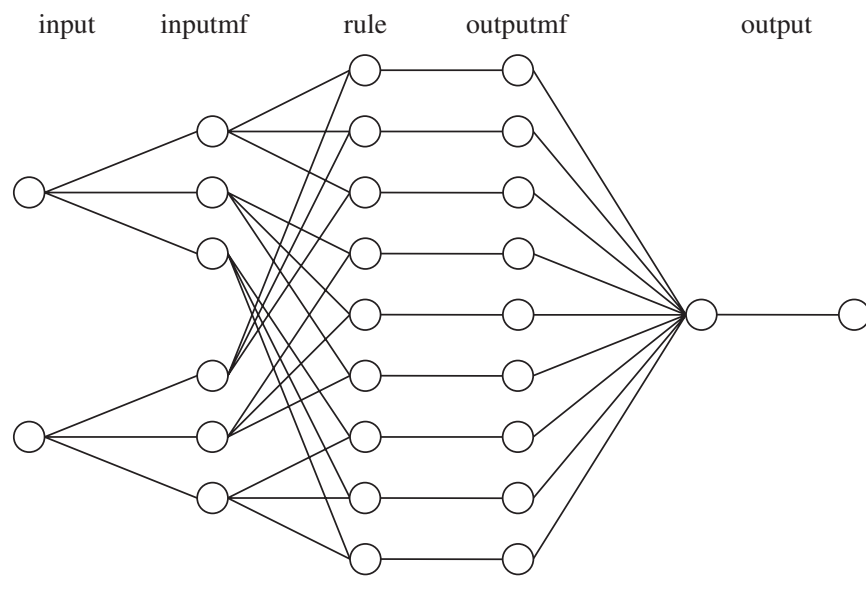

$\begin{array}{llll}\text { Layer1 Layer2 Layer3 Layer4 } & \text { Layer }\end{array}$

Fig. 2. The structure of ANFIS when the inputs were two.

Table 4

The input of each ANFIS model

\begin{tabular}{|c|c|c|c|c|c|c|c|}
\hline Group & $\begin{array}{l}\text { Parameter } \\
r \\
\text { Code }\end{array}$ & $\begin{array}{l}\text { PAC }(t-2) \\
0.749\end{array}$ & $\begin{array}{l}\text { PAC }(t-1) \\
0.822\end{array}$ & $\begin{array}{l}\text { RWT }(t) \\
0.608\end{array}$ & $\begin{array}{l}\text { FWT }(t) \\
0.596\end{array}$ & $\begin{array}{l}\text { RWC }(t) \\
0.496\end{array}$ & $\begin{array}{l}\text { FWC }(t) \\
0.500\end{array}$ \\
\hline \multirow[t]{5}{*}{ ANFIS1 } & FN001 & & & I & I & I & I \\
\hline & FN002 & & & I & I & & I \\
\hline & FN003 & & & I & I & & \\
\hline & FN004 & & & & I & & \\
\hline & FN005 & & & I & & & \\
\hline \multirow[t]{5}{*}{ ANFIS2 } & FN001n & & I & I & I & I & I \\
\hline & FN002n & & I & I & I & & I \\
\hline & FN003n & & I & I & I & & \\
\hline & FN004n & & I & & I & & \\
\hline & FN005n & & I & I & & & \\
\hline \multirow[t]{5}{*}{ ANFIS3 } & FN001nn & I & I & I & I & I & I \\
\hline & FN002nn & I & I & I & I & & I \\
\hline & FN003nn & I & I & I & I & & \\
\hline & FN004nn & I & I & & I & & \\
\hline & FN005nn & I & I & I & & & \\
\hline \multirow[t]{2}{*}{ ANFIS4 } & FN006n & & I & & & & \\
\hline & FN006nn & I & I & & & & \\
\hline
\end{tabular}

that the proposed ANFIS classifier has potential in detecting the ophthalmic arterystenosis.

In order to evaluate the resultant model of ANFIS that is not biased toward the training data set and is likely to have a better generalization capacity to new data, the data sets were divided into training and testing data sets. The databases were divided into 699 and 120 data points in the training and testing sets, respectively. When the consequent part of ANFIS is composed of Sugeno-type fuzzy rule with the first-order linear equation, and three membership functions are used for each input parameters, and the membership function was Gaussian function. The training's epochs were 200 times. According to Pearson factor, the number of model inputs used in this study ranges from 1 to 6 , where this study consists of 17 models (Table 4).

\section{Results and discussion}

\subsection{ANN model}

All ANN models can be divided into four groups including ANN1, ANN2, ANN3, and ANN4 group (Table 3). The input parameters of each ANN1 model were the different water quality parameters not including PAC dosage factor. The input parameters of both ANN2 and ANN3 models were the same as ANN1, besides PAC dosage factor. The difference between ANN1's and ANN2's input parameters were the PAC dosage of yesterday. The difference between ANN1's and ANN3's input parameters were the PAC dosage of yesterday and before yesterday. The input parameters of ANN4 were the PAC dosage of yesterday and before yesterday. The $R^{2}$ and RMSE of each model are shown in Fig. 3.

When the input parameters were only used as the water quality parameters, the predicting ability of models was lower than the input parameters, including PAC dosage factor. The group of ANN2 model was better than the group of ANN1 model. Because the group of ANN2 model was better than the group of ANN3 model, it was evident that the input parameters that were used by PAC dosage of yesterday were better than PAC dosage of yesterday and before yesterday.

The $R^{2}$ of model is above 0.85 , including the seven models as shown in Table 5. The optimal coagulant predicting model was the inputs including the turbidity of raw water and the PAC dosage of yesterday. The $R^{2}$ and RMSE were 0.9256 and 0.00356 , respectively, as shown in Fig. 4. The optimal self-predicting model was when the inputs were PAC dosage of yesterday and the PAC dosage before yesterday. The $R^{2}$ and RMSE were 0.8685 and 0.00424 , respectively.

\subsection{ANFIS model}

All ANFIS models can be divided into four groups, including ANFIS1, ANFIS2, ANFIS3, and ANFIS4 (Table 4). The input parameters of each ANFIS1 model were the different water quality parameters not including PAC dosage factor. The input parameters of each ANFIS2 and ANFIS3 model were the same as ANN1 other than PAC dosage factor. The difference between ANFIS1 and ANFIS2 was the input parameter of PAC dosage of yesterday. Otherwise the difference between ANFIS1 and ANFIS3 were the input parameters were of PAC dosage of yesterday and before yesterday. The input parameters of ANFIS4 were the PAC dosage of yesterday and before yesterday. The $R^{2}$ and RMSE of each model are shown in Fig. 3.

When the input parameters were only used as the water quality parameters, the predicting ability of models was lower than the input parameters including PAC dosage factor. The group 
a

The group of model

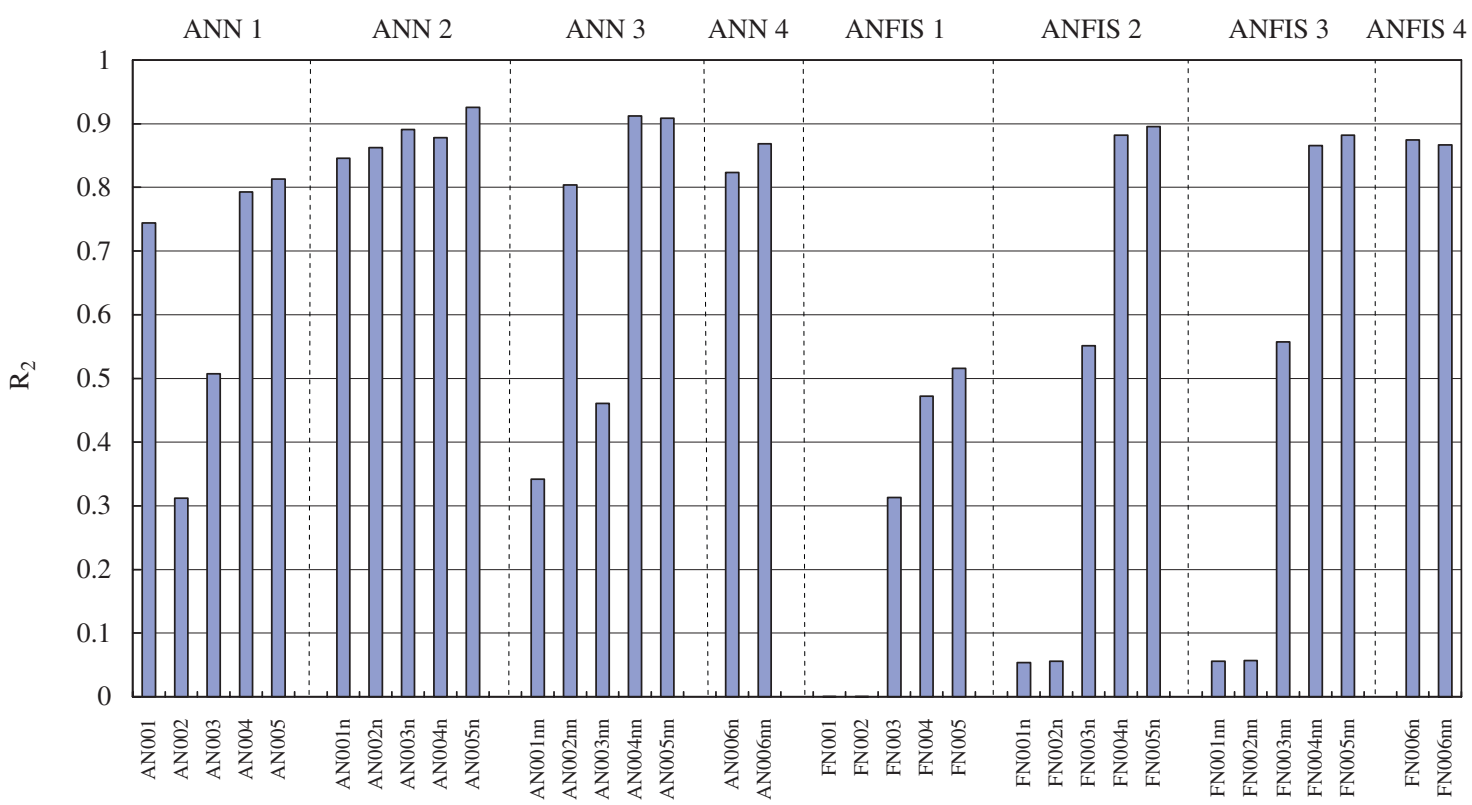

The code of model

b

The group of model

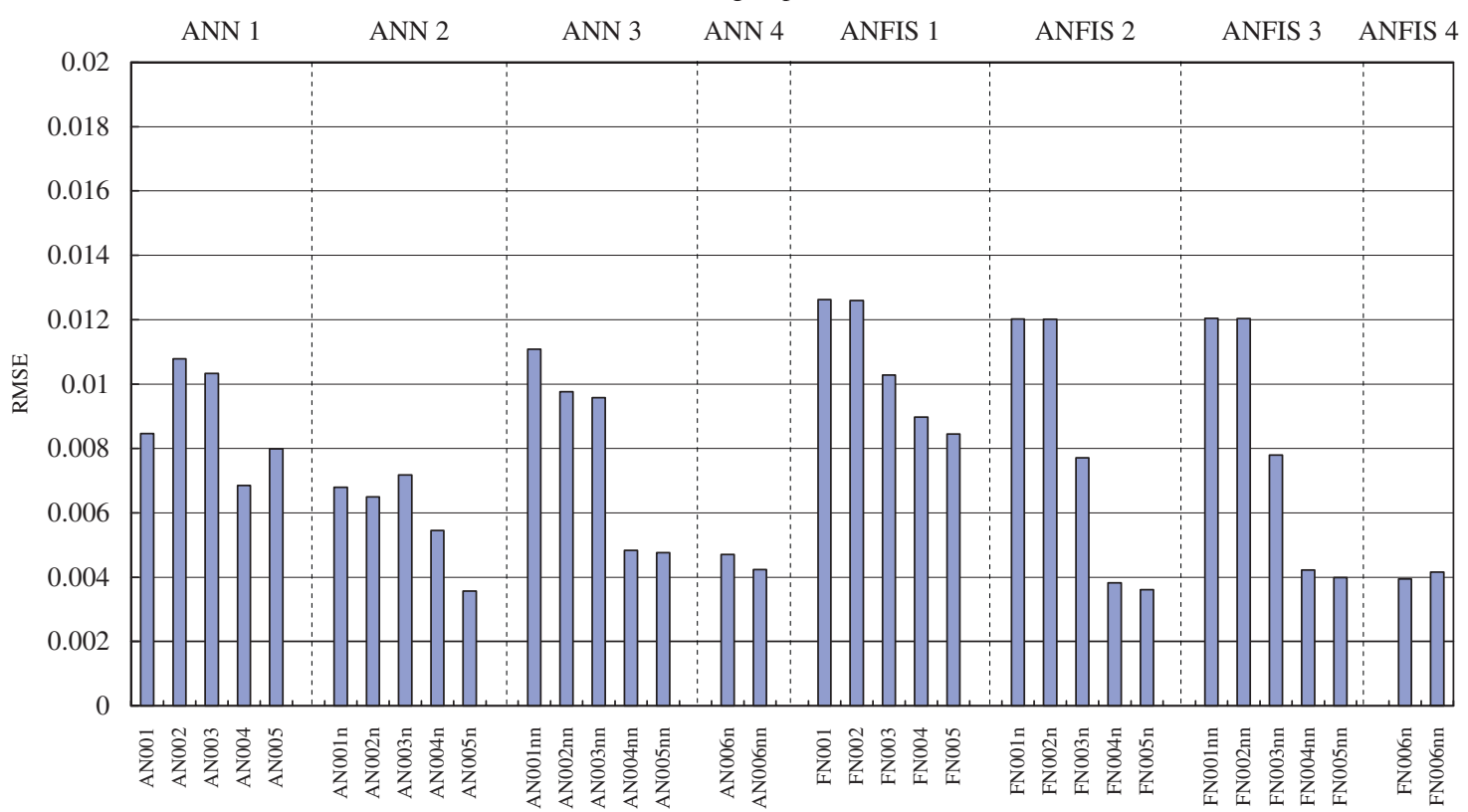

The code of model

Fig. 3. The $R^{2}$ and RMSE of each model: (a) the $R^{2}$ and (b) the RMSE.

Table 5

The better model of ANN

\begin{tabular}{llllllll}
\hline & PAC $(t-2)$ & PAC $(t-1)$ & RWT $(t)$ & FWT $(t)$ & FWC $(t)$ & $R^{2}$ & RMSE \\
$r$ & 0.749 & 0.822 & 0.608 & 0.596 & 0.500 & & \\
\hline AN005n & I & I & & & 0.9256 & 0.00356 \\
AN004nn & I & I & & I & & 0.9125 & 0.00483 \\
AN005nn & I & I & I & & & 0.9086 & 0.00476 \\
AN003n & I & I & I & & 0.8908 & 0.00717 \\
AN004n & I & & I & & 0.8778 & 0.00545 \\
AN006nn & I & I & & & & 0.8685 & 0.00424 \\
AN002n & I & I & I & I & 0.8623 & 0.00650 \\
\hline
\end{tabular}

AN005n, AN004nn, AN005nn, AN003n, AN004n, AN006nn, AN002n: the code of ANN model. of ANFIS2 model was better than the group of ANFIS1 model. Because the group of ANFIS2 model was better than the group of ANFIS3 model, it was shown that the input parameter was used by the PAC dosage of yesterday better than the PAC dosage yesterday and before yesterday.

The $R^{2}$ of model is above 0.85 , including 6 models as shown in Table 6. The optimal coagulant predicting model was the inputs including the turbidity of raw water and the PAC dosage of yesterday. The $R^{2}$ and RMSE were 0.8955 and 0.00360 , respectively, as shown in Fig. 5. The optimal self-predicting model was when the input was PAC dosage of yesterday. The $R^{2}$ and RMSE were 0.8744 and 0.00394 , respectively, as shown in Fig. 6. 
a

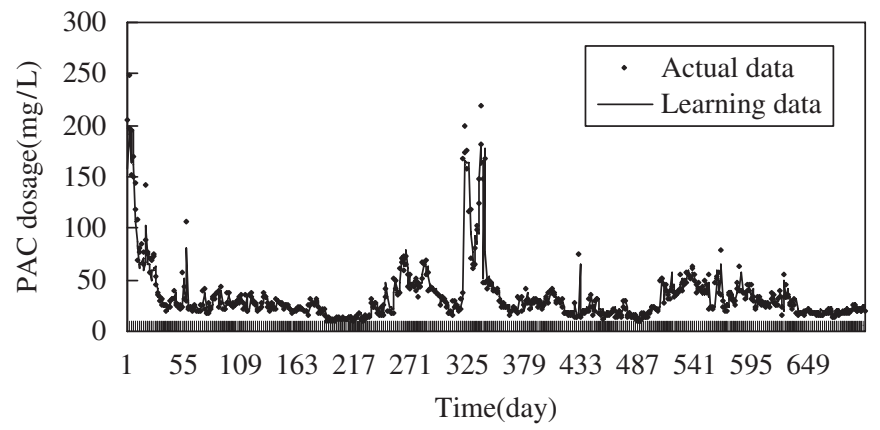

b

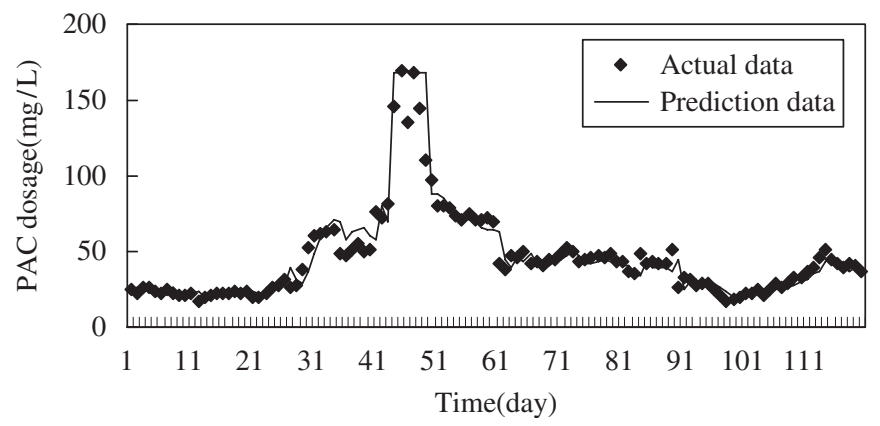

Fig. 4. The optimal model of ANN; the inputs were PAC ( $t-1)$ and RWT $(t)$ : (a) the learning sets, and (b) the predicting sets.

Table 6

The better model of ANFIS

\begin{tabular}{lllllll}
\hline & PAC $(t-2)$ & PAC $(t-1)$ & RWT $(t)$ & FWT $(t)$ & $R^{2}$ & RMSE \\
& 0.749 & 0.822 & 0.608 & 0.596 & & \\
\hline FN005n & & I & I & & 0.8955 & 0.00360 \\
FN004n & & I & & I & 0.8822 & 0.00382 \\
FN005nn & I & I & I & & 0.8821 & 0.00399 \\
FN006n & & I & & & 0.8744 & 0.00394 \\
FN006nn & I & I & & & 0.8667 & 0.00415 \\
FN004nn & I & I & & I & 0.8655 & 0.00422 \\
\hline
\end{tabular}

FN005n, FN004n, FN005nn, FN006n, FN006nn, FN004nn: the code of ANFIS model.

\subsection{The comparison of ANN and ANFIS model}

The ANN2 model group was the best group out of ANN model and ANFIS model, where it achieved higher $R^{2}$ and better RMSE in the solution (Fig. 3). This was evident as the ANN model usually achieves better performance when the input parameters include the water quality and the PAC dosage of yesterday. It means ANN model is suitable to predict the coagulant dosage when the storm water brings high turbidity to water source.

The ANFIS4 model group was better than ANN4 model group, because there was higher $R^{2}$ and better RMSE in the solution. The optimal self-predicting model was built upon ANFIS tools. This lets ANFIS model be suitable to predict the coagulant dosage when influent water does not provide information on water quality.

\subsection{The application of ANN and ANFIS model}

The application of neural network model to WTP is successful. When the storm water brings high turbidity to water source, the optimal coagulant predicting model by ANN, which has inputs including the turbidity of raw water and the PAC dosage of

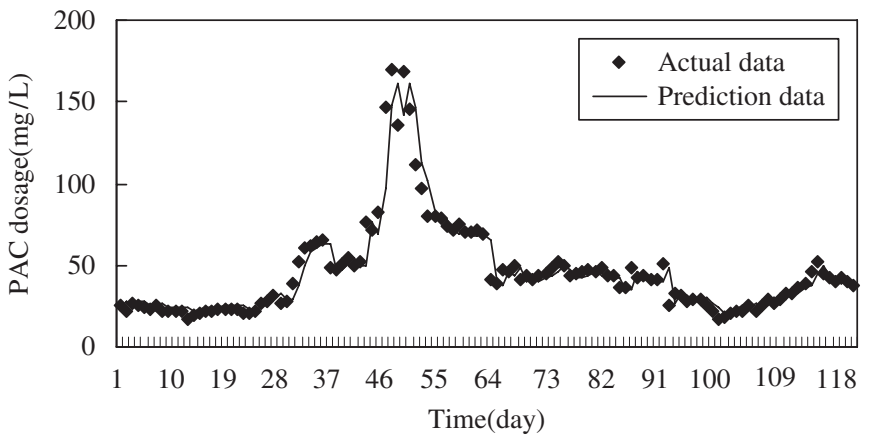

Fig. 5. The optimal model of ANFIS; the inputs were PAC $(t-1)$ and RWT $(t)$.

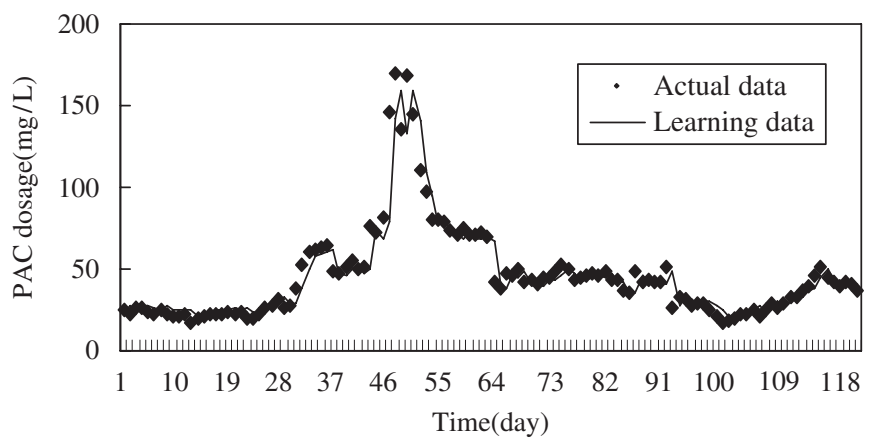

Fig. 6. The optimal self-predicting model; the input was PAC $(t-1)$.

yesterday, can predict the coagulant dosage. Otherwise, when there is no information about the influent water, the optimal selfpredicting model by ANFIS, where the input is PAC dosage of yesterday, can predict the coagulant dosage. Thus it is possible to perform a multivariant design of water treatment alternatives by using the proposed model and system and enabling the user to make computer-aided design using a lot of water treatment alternatives.

\section{Conclusions}

In this study, the ANN and ANFIS models are used to obtain the optimal predicting model for the optimal PAC dosing in real time. The ANN model is better than the ANFIS model to be used to achieve the optimal predicting model for the optimal PAC dosing in real time when the storm water brings high turbidity to water source. The parameters of optimal model can be decided via Pearson factor, which can reduce the quantity of input parameters, and the calculation is done more quickly. In the self-predicting model, ANFIS tools are shown to have better performance than those of ANN, because they can only be used as one input parameter to obtain higher $R^{2}$ and better RMSE in the solution. The operator in WTP can use PAC self-predicting model to determine the PAC dosage daily when influent water does not provide information on water quality. Thus it is possible to perform a multivariant design of water treatment alternatives by using the proposed model and system and enabling the user to make computer-aided design by a lot of water treatment alternatives.

\section{References}

Bae, H., Kim, S., Kim, Y.J., 2006. Decision algorithm based on data mining for coagulant type and dosage in water treatment systems. Water Science and Technology 53 (4-5), 321-329. 
Baxter, C.W., Stanley, S.J., Zhang, Q., 1999. Development of a fullscale artificial neural network model for the removal of natural organic matter by enhanced coagulation. Journal of Water Supply Research and Technology_Aqua 48 (4), 129-136.

Benardos, P.G., Vosniakos, G.-C., 2007. Optimizing feedforward artificial neural network architecture. Engineering Applications of Artificial Intelligence 20 365-382.

Chen, C.-L., Hou, P.-L., 2006. Fuzzy model identification and control system design for coagulation chemical dosing of potable water. Water Science and Technology: Water Supply 6 (3), 97-104.

Chun, M.G., Kwak, K.C., Ryu, J.W., 1999. Application of ANFIS for coagulant dosing process in a water purification plant. In: IEEE International Fuzzy Systems Conference Proceedings. Seoul, Korea, pp. 1743-1748.

Deveughele, S., Do-Quang, Z., 2004. Neural networks: an efficient approach to predict on-line the optimal coagulant dose. Water Science and Technology: Water Supply 4 (5-6), 87-94.

Gagnon, C., Grandjean, B.P.A., Thibault, J., 1997. Modelling of coagulant dosage in a water treatment plant. Artificial Intelligence in Engineering 11, 401-404.

Hecht-Nielsen, R., 1987. Kolmogorov's mapping neural network existence theorem. In: First IEEE International Joint Conference on Neural Networks. San Diego, California, pp. 11-14.

Maier, Holger R., Margan, Nicolas, Chow, Christopher W.K., 2004. Use of artificial neural networks for predicting optimal alum doses and treated water quality parameters. Environmental Modeling and Software 19, 485-494.
Hornik, K., Stinchcombe, M., White, H., 1989. Multilayer feedforward networks are universal approximators. Neural Networks 2, 359-366.

Inan, Guler., Elif Derya, Ubeyli., 2005. Automatic detection of ophthalmic arterystenosis using the adaptive neuro-fuzzy inference system. Engineering Applications of Artificial Intelligence 18, 413-422.

Jang., J.S.R., 1993. ANFIS: adaptive-network-based fuzzy inference system. IEEE Transactions on Systems, Man, and Cybernetics 23 (3), 665-685.

Joo, D.-S., Choi, D.-J., Park, H., 2000. The effects of data preprocessing in the determination of coagulant dosing rate. Water Research 34 (13), 3295-3302.

van Leeuwen, J. Chow, C.W.K. Bursill, D., Drikas, M., 1999. Empirical mathematical models and artificial neural networks for the determination of alum doses for treatment of southern Australian surface waters. Journal of Water Supply Research and Technology-Aqua 48 (3), 115-127.

White, H., 1989. Learning in artificial neural networks: a statistical perspective. Neural Computation 1, 425-464.

Yu, R.-F., Kang, S.-F., Liaw, S.-L., Chen, M.-C., 2000. Application of artificial neural network to control the coagulant dosing in water treatment plant. Water Science and Technology 42 (3-4), 403-408.

Zhang, Q., Stanley, S.J., 1999. Real-time water treatment process control with artificial neural networks. Journal of Environmental Engineering, ASCE 125 (2), 153-160.

Zurada, J.M., 1992. Introduction to Artificial Neural Systems. PWS, Singapore, pp. 195-196. 